\title{
TURISMO ARQUEOLÓGICO COMO ALTERNATIVA DE DESARROLLO LOCAL EN LA RIVIERA MAYA, QUINTANA ROO
}

\author{
Rosa Isela Fernández Xicotencatt* \\ Universidad de Quintana Roo \\ Álvaro Martín Vázquez Leyva** \\ Instituto Politécnico Nacional \\ Alejandro Palafox-Muñoz,*** \\ Universidad de Quintana Roo
}

\section{RESUMEN}

Este trabajo expone la importancia del turismo arqueológico en la Riviera Maya de Quintana Roo, México, como una alternativa para el desarrollo local comunitario. A través de la construcción de un marco conceptual crítico, se parte de la tesis de que existen zonas arqueológicas descubiertas por las comunidades rurales y locales que no son reconocidas formalmente por la autoridad estatal y federal para su promoción turística y en beneficio económico para estas comunidades. Mediante observaciones participantes, entrevistas semiestructuradas y a profundidad con actores locales, los resultados muestran que además de la existencia de numerosos vestigios arqueológicos para llevar a cabo esta actividad, las comunidades han construido otra forma de ser y hacer turismo, contrapuesto a la idea dominante de este último como mercancía. La política encaminada al turismo arqueológico es contradictoria, y se recomienda que aquéllas formas emergentes de turismo arqueológico se reconozcan y apoyen como una actividad autónoma respecto del turismo oficial.

Palabras clave: Turismo arqueológico, Desarrollo local, Fetiche, Globalización, México.

Recibido: 2 de marzo de 2016

Devuelto para su revisión: 30 de junio de 2016

Aceptado: 20 de octubre de 2016

* Avenida Andrés Quintana Roo s/n, con 110 Sur frente a la Colonia San Gervacio, C.P. 77600, Cozumel, QUINTANA ROO, México. E-mail: f.isela@gmail.com

** Prolongación de Carpio 471, Colonia Plutarco Elías Calles, Delegación Miguel Hidalgo, C.P. 11340, México, CIUDAD DE MÉXICO. E-mail: amartin_vazquez@live.com.mx

**** Avenida Andrés Quintana Roo s/n, con 110 Sur frente a la Colonia San Gervacio, C.P. 77600, Cozumel, QUINTANA ROO, México.E-mail: alejandro.palafox.munoz@gmail.com 


\title{
Archaeological tourism alternative for local development in the Riviera Maya, Quintana Roo
}

\begin{abstract}
This paper discusses the importance of archaeological tourism in the Riviera Maya of Quintana Roo, Mexico, as an alternative for local community development. Through the construction of a critical conceptual framework it is part of the thesis that there are archaeological sites discovered by rural and local communities that are not formally recognized by state and federal authority for tourism promotion and economic benefit to these communities. Through participant observation, semi-structured interviews and in depth with local actors, the results show that in addition to the existence of numerous archaeological remains to carry out this activity, communities have built another way of being and sightseeing, as opposed to the dominant idea of this as a commodity. The policy aimed at archaeological tourism is contradictory, and it is recommended that those emerging forms of archaeological tourism is recognized and supported as an autonomous activity for the tourism official.
\end{abstract}

Keywords: Archaeological tourism, Local development, Fetish, Globalization, Mexico.

\section{INTRODUCCIÓN}

El turismo es una actividad relevante no sólo como autoaprendizaje personal, sino para el crecimiento y desarrollo de un país en términos económicos, sociales y culturales, ya que genera y promueve la afluencia de recursos de capitales en la dinámica del mercado interno nacional y extranjero (Magaña-Carrillo, 2009). En países como México, con una economía dependiente y escaso o nulo apoyo federal para los municipios y localidades en las entidades estatales monodependientes de esta actividad para su desarrollo, el turismo adquiere una importancia vital de sobrevivencia estratégica, económica y cultural (Cañada, 2007).

De acuerdo con datos de la Organización Mundial del Turismo (2011), el 40\% de los viajes internacionales que se realizaron en 2010, se debieron a motivaciones culturales. Para el caso de México, los datos del Instituto Nacional de Estadística, Geografía e Informática (INEGI) muestran que aun cuando la riqueza cultural del país es muy vasta, en materia de turismo cultural éste representa apenas 5.5\% de los turistas nacionales, y 3\% de los turistas internacionales. El contraste de estas cifras justifica que el gobierno mexicano visualice al patrimonio cultural como una forma de capitalizar el pasado cultural del país como estrategia de políticas para la atracción y obtención de los capitales extranjeros (Fernández y Guzmán, 2002).

No obstante, es indiscutible que la política turística del país sólo ha beneficiado a las grandes corporaciones hoteleras y agencias de turismo que tienen el potencial y los recursos para competir en el mercado turístico nacional (Palafox, 2013). Para poder subsistir, las pequeñas localidades en los municipios del país, donde las políticas sectoriales no han cumplido con su propósito, encuentran en la actividad turística la única forma de ser 
incluidas en la lógica del mercado turístico (Palafox y Martínez, 2015).En la mayoría de los casos estas localidades desarrollan formas de autorganización comunitaria en el aprovechamiento de sus conocimientos tradicionales y actuales, en la riqueza de sus recursos naturales y/o arqueológicos y, en general, en sus patrimonios culturales como forma de acción colectiva emergente y alternativa que compensa el vacío institucional dejado por la política turística gubernamental. De ahí que sea necesario realizar un breve análisis sobre las políticas del turismo nacional. Estas políticas se caracterizan por la implementación de estrategias y acciones para potenciar cultural y económicamente a aquellas zonas del país que son designadas institucionalmente como «turísticas». Conceptualmente, esta visión de políticas se distingue por una idea implícita del turista (nacional y extranjero) como un agente pasivo, restringido a desempeñar únicamente el papel de «consumidor» de la cultura, y no como un sujeto con capacidad de acción y decisión. Esto ya fue abordado por la sociología como «tensiones entre las formas tradicionales y modernas», impulsadas por los procesos amplios de modernización del capital global en la forma de globalización, y el consecuente deterioro de las formas de organización y valores tradicionales en la pluralidad de los ethos locales. En realidad el problema de fondo está relacionado con la definición que se tenga del concepto de cultura. En pocas excepciones éste es definido de manera explícita en los discursos institucionales. Esta problemática nos lleva a aseverar que en el contexto de la globalización económica y del paradigma economicista que lo sustenta, el marco de racionalidad de los diseñadores de las políticas culturales y turísticas del país supone una concepción de la cultura en cuanto a su valor de cambio, es decir, a su sólo valor economicista como mercancía, rentabilidad y ganancia.

A primera vista esta asunción económica parecería la respuesta más lógica y eficaz ante la necesidad de desarrollo del país insertado en los circuitos del mercado en la presente globalización. Sin embargo, la consecuencia inherente a esta acción es el sacrificio del valor de uso de la cultura, esto es, de la riqueza multivariada que el concepto representa en cuanto a su sentido simbólico, místico, religioso, cosmogónico, lingüístico, estético y material.

Las poblaciones de las localidades «turísticas» son las que recienten de manera directa y dramática el efecto de aquéllas acciones. La unidimensionalidad y homogeneidad de las políticas del turismo nacional determinan el horizonte de comprensión desde el cual estas localidades son percibidas, tipificadas y clasificadas socialmente como «agentes turísti$\cos »$, y no como genuinos propietarios originarios de la riqueza de su cultura comunitaria.

Por el contrario, desde la perspectiva de estas poblaciones locales, no sólo se trata de impulsar su desarrollo económico territorial sino que, en función de sus usos y costumbres, la finalidad primordial es insertarse en lo global manteniendo su especificidad local; y esto implica defender el uso del segundo concepto de cultura antes mencionado, así como readecuar la normatividad legislativa que regula al turismo nacional.

El quid pro de la cuestión es entonces la definición de las políticas turísticas desde abajo hacia arriba (bottom-up), con la participación colectiva y organizada de las localidades del país; pero sobre todo, de aquellos territorios locales que no logran satisfacer los requisitos y estándares solicitados por la normatividad de las políticas del sector turístico oficial y sus dependencias (Instituto Nacional de Antropología e Historia -INAH-, Secretaría de Turismo -SECTUR-, etc.) para ser reconocidas como «zonas 
turísticas», o que no son integradas en la nueva modalidad oficial denominada «Pueblos Mágicos» ${ }^{1}$, y así recibir los recursos y apoyos institucionales correspondientes.

Este «vacío» de políticas del turismo paulatinamente es colmado por acciones colectivas de iniciativas locales a través de formas de autorganización en asociaciones y grupos civiles para la promoción y atracción del turismo, y que van más allá del horizonte del marco de comprensión institucional. El avance de estos colectivos ha dado pie a la implementación de otras formas de imaginar y recrear el turismo mediante una participación activa e incluyente del turista, con un sentido de conocimiento y comprensión de la historia y actualidad de la cultura, así como de una interacción responsable con la geodiversidad y biodiversidad en que se encuentra. Por ello las formas de organización, los problemas y obstáculos que enfrentan, así como el impacto en el turismo local, entre otras cuestiones, constituyen temas que no han sido abordados en su justa dimensión por las ciencias sociales en nuestro país.

Con todo, este trabajo busca abordar al turismo alternativo en una de sus modalidades principales: el turismo arqueológico. El trabajo se estructura en el orden siguiente: la primera parte se basa en el análisis crítico de diferentes conceptos y corrientes teóricas sociales a fin de desmitificar la idea común que se tiene sobre la globalización y el turismo, revelando su esencia capitalista y de consumo en ambos conceptos, así como los correspondientes cambios en la identidad de los individuos para así comprender el tipo de turismo dominante que se ejerce en la actualidad. La segunda parte analiza la concepción etimológica y semántica del concepto «turismo» para diferenciar las dos formas de ser y hacer turismo en la actualidad. La tercera aborda las implicaciones del turismo en el desarrollo económico nacional, y se describe la metodología a utilizar. En la cuarta parte se explica al turismo arqueológico como alternativa de desarrollo local para la Riviera Maya; también se muestran las limitaciones y obstáculos en la política del turismo nacional, y se analizan los testimonios derivados de algunas reservas ecológicas comunitarias que cuentan con vestigios arqueológicos, con la finalidad de mostrar las dificultades que enfrentan para conservar estos lugares y el modo en que comprenden la forma de hacer turismo. Finalmente, se exponen las conclusiones que buscan reflexionar y dialogar sobre el papel que deben desempeñar los actores externos a fin de apoyar estas actividades.

\section{LA GLOBALIZACIÓN: HACIA SU ESENCIA ECONÓMICA}

\subsection{El turismo como fetiche de la globalización}

En la actualidad es frecuente encontrar en la literatura científica social -a veces más esotérica que como tal-, afirmaciones que consideran que la globalización es ya parte de la cotidianidad, lo que vale decir: una forma «naturalizada» de convivencia humana e inevitable ${ }^{2}$.

1 Actualmente la Secretaría de Turismo incluye al turismo arqueológico dentro del turismo cultural, y a éste junto con otras denominaciones, tales como: Rutas Gastronómicas, Rutas de México, Pueblos Mágicos, Mundo Maya, Casas de Artesanía, Galerías de Arte, Museos, Paseos Culturales y Religiosos, y Teatros, sin mayor esfuerzo de precisión y distinción conceptual.

2 Véase así, por ejemplo, a Mario Vargas Llosa (2000), y el reavivamiento de la obra de Francis Fukuyama (1992). 
Desde esta generalización, el turismo se presenta como una actividad consustancial a la iniciativa y deseo individualista del espíritu occidental moderno, aventurero y cosmopo$\operatorname{lita}^{3}$, en el que elementos que son patrimonio de las culturas originarias -ajenas al proceso mismo de la modernidad-son desanclados de sus raíces culturales y puestos como oferta para el consumo en un mercado turístico internacional.

Estas definiciones son las que conciben al turismo como un sistema que abarca diversos procesos de interacción en los que se encuentran involucrados un amplio espectro de agentes: población local, potenciales turistas, trabajadores foráneos, micro, medianas y macro empresas, etc., y no un menor abanico de espacios cargados de significados y simbolizaciones (Meethan, 2001, citado en Santana Talavera, 2003).

Como simple producto de la globalización, el turismo es asociado al mercado en la forma de comercialización de la cultura y de la naturaleza. De este modo, el turismo es construido como una actividad del gusto individual de las personas de los países industrializados que desean conocer de manera exótica el folklore y entorno natural de las culturas de los países no desarrollados. Los medios de comunicación son el actual vehículo principal de expansión de esta ideología.

En esta fase del capitalismo como globalización, prevalece el poder de la imagen de los mass media y de la individualización como base de despliegue de la sociedad de consumo mercantil. Así pues, no extraña que el turismo sea frecuentemente relacionado con la globalización y como un producto «nuevo», como una «moda», como una manera de ser y estar in, como un estilo de vida, como una distinción de clase y gusto social, y, lo más importante: la figuración de que el turismo está al «alcance» de toda persona que disponga de tiempo «libre» ${ }^{4}$.

Esta ideologización oculta las relaciones de fuerza y poder que sustenta y acompaña la evolución del sistema capitalista presente: la explotación de los recursos naturales por parte de grandes empresas turísticas a través de técnicas de gestión y mercadológicas dirigidas a la instrumentalización del turismo. Protegido de todo contenido político, cultural y social de la vasta complejidad de las diversas realidades locales en las que el turismo en última instancia adquiere su sentido y significados concretos, éste se racionaliza en una estrategia moderna de apropiación y mercantilización de las culturas y saberes ancestrales locales de los países no avanzados. Por lo tanto, así reflexionado, el turismo se ha convertido en un fetiche (Marx, 1985).

Se requiere pues de una reflexión crítica que desmitifique el concepto dominante e ideológico de globalización, y por añadidura, del turismo, tal como lo expone Joahim Hirsh (1996:95-96) en los términos siguientes:

3 Ejemplo de estas definiciones sobre el turismo son las que lo conciben como: «El conjunto de actividades que realizan las personas durante sus viajes a lugares distintos de su contexto habitual, por un periodo inferior a un año, con propósitos de ocio, negocios y otros motivos» (Organización Mundial de Turismo, 2011).

4 Este es otro fetiche que gestiona la mercadotecnia turística de las grandes firmas hoteleras: en realidad el adjetivo «libre» oculta el hecho de que el uso del tiempo individual y colectivo es promovido y orientado por el Estado, las empresas privadas y los mass media, por citar a los más determinantes; y se hace creer al individuo en la ficción de su soberana decisión sobre qué hacer con «su» tiempo. En verdad, el aspecto esencial es que hay personas que por factores de posición de clase, capital cultural y económico, sexo y edad, etc., están en mejores condiciones que otras para usar el tiempo socialmente disponible en actividades fuera de la esfera del trabajo. 
En el mundo de las apariencias, la «globalización» representa cosas muy variadas: Internet, Coca-Cola, televisión vía satélite, IBM, libre comercio, correo electrónico, triunfo de la «democracia» sobre el «consumismo», «tratado de libre comercio», telenovelas de Hollywood, Microsoft, catástrofes climáticas, acaso también la Organización de las Naciones Unidas y las intervenciones militares «humanitarias» realizadas bajo su nombre. [...] La «globalización», es, así, algo más que un concepto científico. De cierta manera, hoy en día es un fetiche. Es decir, la palabra se utiliza con frecuencia sin ser entendida en detalle, significando muchas veces lo opuesto, pero teniendo algo en común: describe algo así como un poder oculto que agita al mundo, que determina toda nuestra vida y que nos domina cada vez más.

Ese «poder oculto» al que hace referencia Hirsh, es la generalización mundial de la ley del valor del capital: «La globalización se refiere, en esencia, a un proceso económico» (Hirsh, 1996:98). Si esto es así, y como se describió en líneas anteriores, el turismo entonces se encuentra ideológicamente relacionado con ésta; por consiguiente, no sólo las mercancías «entran» en el proceso de la circulación y competencia del capital, sino también las personas, en su forma fetichizada y cosificada de mercancías «corporeizadas» como valor de cambio.

En esta lógica argumentativa no extraña que el turista se perciba a sí mismo como un «libre» consumidor con derechos asegurados (en realidad, derechos de consumo) por las grandes empresas hoteleras y por la política turística nacional del país a donde llega, sin mayor sentido de compromisos empáticos con las realidades culturales locales. Es por ello que es necesario realizar un acercamiento más a fondo de estas cuestiones, como se expone enseguida.

\section{DEL TURISTA COMO SUJETO AUTORREFLEXIVO AL TURISTA COMO CONSUMIDOR DE CULTURA}

\subsection{El turismo como relación cognoscitiva con la cultura}

En las representaciones colectivas de las sociedades modernas occidentales se considera al turismo como conocimiento del sentido común. Basta con asistir a los sistemas de transporte colectivo nacional e internacional (estaciones de autobuses, de ferrocarriles o de aeropuertos) y se «encontrarán» al turismo y a los turistas. Por ello no sorprende la sencillez con que se define al turismo y turista en el Diccionario de la Real Academia Española. Este último, entiende el vocablo de tourism como derivado del idioma inglés, y que significa: «actividad o hecho de viajar por placer; conjunto de los medios conducentes a facilitar estos viajes, y conjunto de personas que realiza este tipo de viajes» (Real Academia Española, 2015).

Desde el siglo XII, la teoría latina europea ha compartido también esta idea inglesa de viajar como sinónimo de turismo ${ }^{5}$. Aunque es importante señalar que lo característico de

5 Desde esta teoría, turismo deriva del latín tornus, igual a torno; y de tornare, igual a redondear, tornear, girar. Por consiguiente, turismo equivale a «la actividad que realizan las personas que consiste en viajar y que además tienen la intención de retornar a su domicilio actual». 
aquella época es que el turismo estaba reservado exclusivamente a una élite intelectual aristócrata y, posteriormente, burguesa. En la mitad del siglo XVIII, para la nobleza inglesa el turismo (turn, para ella) adquiere un sentido diferenciador del resto de los estratos de la pirámide social, así como un sentido pedagógico: viajar a otras regiones territoriales en búsqueda de educación y cultura para aprender sobre el arte de gobernar. En estos términos los célebres Viajes de Marco Polo ${ }^{6}$, tendrían un propósito de aprendizaje, aunque con la intención principal por encontrar rutas de expansión del mercado europeo hacia otros territorios inexplorados, más allá del temprano horizonte burgués capitalista.

Es con la modernidad europea de principios del siglo XX que el turismo adquiere las características de fenómeno de masas y migratorio debido a las transformaciones estructurales socioeconómicas del desarrollo de los procesos de industrialización capitalista posterior al término de la Segunda Guerra Mundial (e intrínsecamente relacionadas con el desarrollo de la globalización, como se expuso en el apartado anterior). El turismo, entonces, paulatinamente comienza a racionalizarse como una actividad socioeconómica, pero sin perder su acepción de actividad viajera. No obstante, a pesar de los cambios estructurales, no sucedió lo mismo con su concepción semántica.

Esto último ha sido el motivo por el cual en la época presente se tiene una representación reduccionista (como fenómeno económico y de consumo individual) del hecho social del turismo en el marco de racionalidad de las políticas de turismo, como se describe a continuación.

\subsection{El turismo como experiencia mediática y narcisista}

Inicialmente se afirmó que en las políticas del turismo nacional e internacional subyace un modo de tipificar al turista: como agente pasivo. El fundamento de esta aseveración subyace en la orientación de la economía mundial hacia el consumo mercantil y en la estrategia de seducción centrada en el Yo narcisista individual como productos del devenir histórico de la modernidad y de la globalización?

En efecto, el desarrollo de la racionalidad del mundo del mercado capitalista ha sido directamente proporcional a la fetichización de los medios en fines (Weber). La reducción de las infinitas posibilidades de experiencia humana en el sólo código costo-beneficio, ha promovido una sensación colectiva de «pérdidas» de sentido expresadas en los valores éticos y humanos, la responsabilidad social, los metarrelatos, las certezas, las utopías, los

6 Nos atrevemos a decir que incluso el mismo Marco Polo, constituyó el prototipo de «turista tradicional» con fines de autoconocimiento y de autorreflexión, contrapuesto al «turista moderno», entendido como la sola búsqueda de aventura y fama.

7 La Ley Federal de Turismo del gobierno mexicano, en su artículo tercero, entiende como «turista» a «[...] la persona que viaja desplazándose temporalmente fuera de su lugar de residencia habitual y que utilice alguno de los servicios turísticos a que se refiere esta Ley». Asimismo, en su artículo cuarto, señala que «servicios turísticos» son los que se prestan a través de hoteles, moteles, albergues y demás establecimientos de hospedaje; agencias, subagencias y operadoras de viajes; guías de turistas; restaurantes, cafés, bares y centros nocturnos que se encuentren ubicados en los establecimientos de hospedaje, así como en aeropuertos, terminales de autobuses, estaciones de ferrocarril, museos y zonas arqueológicas; y empresas de sistemas de intercambio de servicios turísticos (Ley Federal de Turismo,www3.diputados.gob.mx/.../Ley_Federal_Turismo.pdf, consultada el 13 de enero de 2016). Como se aprecia, hay una tendencia a homogeneizar la diversidad de formas en que se expresa el turismo, y una idea simplista del turista, como nómada. 
valores de uso social, etc. Si en la década de los cuarenta el problema del psicoanálisis eran la neurosis e histeria como signos del malestar de la cultura en las personas, en la presente era de la globalización y la exclusión estos signos están representados por la depresión colectiva e individual. Las personas buscarán lo que esté a su alcance para paliar, momentáneamente, el sentimiento de vacío existencial debido al predominio asfixiante de la cultura individualista y sus valores materiales (Bauman, 2003).

Bajo una economía del consumo y la seducción, el culto al ego narcisista es la pieza que corona la estrategia de mercado. De este modo, el turismo es la nueva adicción de las personas de estrato económico elevado que buscan en éste un escape confortable, pero efímero, frente a los problemas de dotación de sentido como experiencia duradera de sus realidades cotidianas (Bauman, 2003; Guzmán, Garduño y Zizumbo, 2009).

Entonces, como consumidor de cultura, lo anterior obliga a que la satisfacción del turista sea inmediata, es decir, al momento fugaz en que se toma una foto «selfie» en el lugar turístico que visita y de la rapidez para que ésta esté circulando en la red social Facebook. El llamado «like» a la foto culmina este proceso, junto con la respectiva insuflación del ego narcisista del turista ${ }^{8}$. La adquisición de conocimiento, formas de socialización y toma de conciencia que pueda generarse en el turista en su interacción con la realidad sociocultural del lugar, constituyen un obstáculo a superar. Viajar, no aprender, es la habilidad que debe desarrollar el turista como condición previa y emotiva para la puesta en marcha del mercado de la seducción turística (Bauman, 2003).

No sorprende entonces que los viajes turísticos a zonas arqueológicas o naturales se reduzcan al tiempo mínimo indispensable que dura el recorrido establecido por el guía de turistas o por el programa turístico del hotel o agencia de viajes: los turistas no deben fijar su atención ni concentrar su deseo en un objeto, sujeto o aspecto de su interés por mucho tiempo. Aprender más allá de la información contenida en la guía de viaje, está prohibido. El turismo, así, no es aprendizaje duradero, sino colección de experiencias efímeras objetivadas en fotos y videos. Las agencias de turismo evitan al hombre moderno todo gasto físico superfluo, aunque fuese para ir al encuentro del asombro y misterio que pueden contener las localidades arqueológicas. Se decapita del turismo el encuentro directo, cara a cara, con lo esencial de las culturas locales. De este modo, el turismo se ha vuelto acéfalo, y los turistas, en nómadas iletrados conectados.

Sin embargo, otros autores (Beltrán y Rojas, 1998; Moreré, 2006; Carballo-Sandoval, 2005) defienden una posición contraria a la nuestra: señalan que hay una clasificación del perfil de turistas en arqueología. Estos turistas se caracterizan por poseer capital cultural y económico por arriba de la media nacional. Son apasionados por la arqueología, la historia y la cultura. Mencionan además que el turismo arqueológico es un segmento de mercado muy especializado, caracterizado por turistas responsables que buscan la conservación de los vestigios antiguos, la riqueza cultural y social del sitio arqueológico, así como un armonioso entorno físico-ambiental de las culturas.

8 La expresión concreta de estas afirmaciones es la reciente vejación de las ruinas arqueológicas de Tulum, en el estado de Quintana Roo, México, por parte de la estrella canadiense del pop musical, Justin Bieber (The Guardian. «Justin Bieber thrown out of Mexico's Tulum ruins, official says», en: http://www.theguardian. com/music/2016/jan/08/justin-bieber-tulum-mayan-ruins-mexican-official-says, consultado el 13 de enero de 2016). 
Aunque es aceptable y se reconoce el desarrollo del perfil turístico por ellos señalado, la pregunta que nosotros anteponemos es: ¿cuántas personas cumplen con los criterios de aquél perfil? La respuesta es: solamente una élite selecta. El grueso de los turistas que, a pesar de que cumplen también con altos niveles educativos y socioeconómicos, lamentablemente también son apasionados y motivados por la bizarra cultura mediática del New Age: encontrar la «huella de los extraterrestres» en las zonas arqueológicas. Todo guía y arqueólogo de cualquier sitio arqueológico puede dar cuenta de ello.

En esta desvirtualización del turismo que se promueve en la lógica económica y consumista que exponemos, tanto el turista como los lugareños de las culturas locales son desanclados (Giddens, 1993) de sus contenidos espaciales y temporales; y las posibles experiencias variadas, ricas de sentido significativo y duraderas, son reducidas al instante efímero con que se desecha un producto del mercado. Desde que las «fronteras naturales» en el proceso de globalización dejaron de ser un obstáculo espacial, jamás se permanece el tiempo suficiente en el lugar turístico para ser algo más que un simple turista (Bauman, 2003:103); pues los turistas, al igual que las mercancías, requieren estar en constante y veloz movimiento para su valorización económica en estas últimas, y su desvalorización humana en aquéllos.

Para no quedar excluidas por la inequidad del mercado turístico en manos de los grandes consorcios que monopolizan el mercado turístico, las comunidades locales, muy a su pesar, han tenido también que seducir a los turistas eventuales para poder atraerlos y tener alguna escasa posibilidad de competir en esta vorágine esquizofrénica de conquista global de ganancias y más ganancias llamada «desarrollo económico» (Bauman, 2003:105).

Llegados a este punto, y para poder capitalizar en lucro todo lo anterior, la industria turística ha montado una compleja organización estratégica de la economía para la explotación de las culturas locales y de su entorno natural, como se desarrolla en las reflexiones siguientes.

\section{LA ORGANIZACIÓN DEL TURISMO COMO ACTIVIDAD ECONÓMICA}

\subsection{El turismo nacional: ¿beneficio económico para todos?}

En los países latinoamericanos la globalización ha provocado la exclusión de etnias y marginación de las comunidades indígenas. Situación que ha significado la mutación de sus identidades nacionales debido a la ruptura de sus anteriores formas de vida, costumbres y tradiciones (Woynar, 2003). Sin embargo, la región de las Américas obtuvo el mayor crecimiento relativo de todas las regiones del mundo con un incremento del $8 \%$, donde se distingue la escalada de las llegadas a México con un aumento del $20 \%$ con respecto al año anterior. Esto ha representado 16,258 millones de dólares de ingresos por turismo internacional, lo cual, en cuanto a cifras, son resultados positivos. ¿Podría pensarse entonces en una relación directa del tipo de: a mayor exclusión y pobreza de las etnias y comunidades indígenas, mayor crecimiento económico de la industria turística hotelera en la región?

La Organización Mundial de Turismo (2011), refiere que en 2014 el turismo en México obtuvo crecimientos significantes: representó un aumento del $4.4 \%$ respecto al año anterior, lo que se tradujo en 4.8 millones de turistas más, aun cuando la recuperación 
económica a nivel nacional fue lenta desde 2009. Sin embargo, este crecimiento, que representó hasta el 9\% del Producto Interno Bruto (PIB), no se reflejó en el desarrollo de las comunidades cercanas a los destinos turísticos, y provocó que el gobierno mexicano implementara políticas para el crecimiento del turismo dirigidas a captar la inversión extranjera mediante la explotación y administración de los recursos naturales, culturales e históricos (Hussein, 2010). Esto permitió que grandes empresas se establecieran e influyeran en el funcionamiento de empresas locales a través de formas sutiles y no tan sutiles de presión para que se les autorizaran prácticas no sustentables, o se modificaran las leyes con la finalidad de incentivar la inversión (Peric, 2005; Zhao y Li, 2006).

De hecho, las empresas trasnacionales turísticas llegan a tener tanto poder que se hacen cargo de todo: desde el transporte y alojamiento hasta las actividades de entretenimiento. Actividad que se conoce como turismo de enclave, ya que no se cuenta con la toma de decisiones de la población local para operar (Zhao y Li, 2006; López, 2006), fomentando así la expansión económica sin considerar el desarrollo local para la mejora del bienestar de la vida humana en general.

Ahora bien, antes de continuar con nuestra argumentación, es menester describir el siguiente marco metodológico utilizado para los testimonios en este trabajo.

\subsection{Marco metodológico}

La investigación cualitativa es una alternativa para procesos de investigación en donde la percepción social no puede ser descrita a través de generalidades encontradas en las estadísticas o a través de encuestas, ya que pretende la interacción entre individuos que muchas veces no es fácil de observar e indagar con otros instrumentos (Vela, 2008). Por ello, esta investigación está basada en una metodología cualitativa, pues se convierte en una herramienta fundamental para entender la problemática socio-espacial de las comunidades y arqueólogos que se encuentran alrededor de los vestigios arqueológicos recién descubiertos.

Para este tipo de trabajos, investigadores como Goodson y Phillimore (2004) muestran que no sólo las repuestas a una serie de preguntas como lo son una entrevista estructurada, verifican el comportamiento de quien es cuestionado. Los antropólogos sociales recomiendan observar la realidad desde la perspectiva emic, basada en el punto de vista de los actores involucrados para obtener sus opiniones sobre el fenómeno a estudiar (Monterrubio, et al., 2011).

La herramienta específica utilizada en este trabajo fue la entrevista a profundidad y semiestructurada, con la finalidad de comprender la visión de los ejidatarios al encontrar vestigios arqueológicos en su territorio, las problemáticas que enfrentan las comunidades al no ser participativas y, por otro lado, los arqueólogos que realizan su trabajo.

En total, se realizaron 15 entrevistas a residentes locales en el mes de septiembre de 2015, donde se buscó analizar las percepciones de las personas entrevistadas desde su situación y la de sus tierras, ya que en algunos casos aun cuando tenían la seguridad de encontrar vestigios, no buscan declararlo y prefieren no reportar lo que encuentran.

Por ello se buscó establecer una relación de confianza con quienes son dueños de los ejidos y comunidades cercanas, y así captar su realidad, ya que el solo uso de métodos 
cuantitativos resulta corto para entender la dinámica de organización, formas de vida y relatos personales que guardan pensamientos, conductas y emociones reflejadas en la toma de decisiones de los actores (Díaz-Carrión, 2014).

Hasta ahora este tipo de metodología se ha utilizado en trabajos relacionados con temas del turismo comunitario, del empoderamiento de género en comunidades, y de los impactos del turismo (Cambero, 2011; Díaz-Carrión, 2014; Sánchez, 2009); pero muy poco sobre el tema del turismo arqueológico de forma específica para el estado de Quintana Roo, ya que el término de turismo arqueológico no es utilizado por la Secretaría de Turismo, y ésta lo ve en conjunto como parte del turismo cultural del país. Más aún, al relacionarse el turismo arqueológico con la economía local, como se desarrolla en líneas abajo.

\section{EL TURISMO ARQUEOLÓGICO COMO FUENTE DE DESARROLLO LOCAL EN LA RIVIERA MAYA, QUINTANA ROO}

Si bien es innegable que las actividades turísticas constituyen una alternativa para el desarrollo socioeconómico de las regiones, también es cierto que no se busca únicamente maximizar las ganancias, sino empoderar las tradiciones de las culturas ancestrales locales que aún forman parte de la vida cotidiana de sus comunidades mediante proyectos que mejoren su bienestar social.

El turismo, en estos términos, es una alternativa potencial que se relaciona de manera positiva con la economía social ${ }^{9}$ para el desarrollo local (Zizumbo, 2010), ya que conlleva beneficios a largo plazo, tales como: las generaciones de empleo, de capital social, de especialización en actividades productivas, y de mejoras en la calidad de vida de la población local (Gómez, Juste y Fernández, 2011).

El antes referido concepto de economía social se basa en el desarrollo de la pluralidad de Organizaciones de la Sociedad Civil (OSC). Éstas se relaciona a su vez con el Estado, con el mercado y consigo mismas (Valderrama, Fernández, Neme, y Vázquez, 2013). De acuerdo con la tipología propuesta por estos autores, la relación deseable entre estos tres actores es el de la autorregulación de las OSC, tal como la justifican cuando afirman que: «El ideal de esta relación se expresa en que las OSC han alcanzado un alto grado de autodesarrollo organizacional e institucional, son autofinanciables y con gran potencial de profesionalización reflejados en la calidad de servicios que brindan directamente a su población objetivo» (Valderrama, Fernández, Neme, y Vázquez, 2013:43).

9 Según el Consejo Económico y Social Europeo (CESE) lo define como el conjunto de empresas privadas organizadas formalmente, con autonomía de decisión y libertad de adhesión, creadas para satisfacer las necesidades de sus socios a través del mercado, produciendo bienes y servicios, asegurando o financiando y en las que la eventual distribución entre los socios de beneficios o excedentes así como la toma de decisiones, no están ligados directamente con el capital o cotizaciones aportados por cada socio, correspondiendo un voto a cada uno de ellos. La economía social también agrupa a aquellas entidades privadas organizadas formalmente con autonomía de decisión y libertad de adhesión que producen servicios de no mercado a favor de las familias, cuyos excedentes, si los hubiera, no pueden ser apropiados por los agentes económicos que las crean, controlan o financian (Mendiguren, Etxezarreta y Guridi, 2009). 
En consecuencia, una economía social basada en las actividades turísticas locales tendría por último objetivo este autodesarrollo. No obstante, en el contexto latinoamericano se requiere aún de la relación con la esfera estatal. En efecto, bajo la anterior óptica las actividades turísticas locales que se generen no sustituyen ni exentan la responsabilidad del gobierno con las diversas comunidades; al contrario, trabajan con el Estado para defender el establecimiento de servicios públicos, buscando la generación de empleo con remuneraciones equitativas y justas a favor de misiones de carácter social, cultural y ambiental al producir riqueza para el desarrollo local (Neamtan, 2009), sobre todo para nuestro estudio: las zonas arqueológicas en el estado de Quintana Roo, como se observa a continuación.

\subsection{El estado de Quintana Roo y sus zonas arqueológicas}

Según datos del INEGI, en 2015 la población del estado de Quintana Roo en México, era de 1, 529,877 habitantes, con 10 municipios y 3 regiones. La Riviera Maya se encuentra localizada en la Región Norte, y equivale al 6.4\% de todo el territorio del estado, y concentra a 917,800 habitantes, lo que representa el $60 \%$ de la población estatal. Existen 456 localidades, de las cuales 431 están conformadas por menos de 50 habitantes.

Debido al alto grado de migración del estado, los habitantes son atraídos por las actividades del sector terciario, específicamente del sector turístico. Destacan centros turísticos reconocidos en el ámbito internacional, tales como: Cancún, Cozumel y Tulum, entre los dominantes.

Según datos de la SECTUR, en 2014 se registraron 21.2 millones de visitantes turistas a museos y zonas arqueológicas, y de este porcentaje $58 \%$ visitó zonas arqueológicas, de los cuales $70 \%$ fueron nacionales y $30 \%$ extranjeros. Específicamente en el estado de Quintana Roo, como se observa en el Cuadro 1, la afluencia se ha mantenido constante para zonas internacionalmente conocidas como el caso de Tulum y otras como Muyil, que se han vuelto reconocidas como parte del impulso que se le ha dado al turismo comunitario en la Región Sur, ya que presentó una tasa de crecimiento del 56\% en 2014 con respecto al año anterior.

En una entrevista a la delegada del INAH en Quintana Roo, realizada por Valencia (2013), menciona que:

El estado [Quintana Roo] tiene cerca de cincuenta mil kilómetros cuadrados y en este espacio tenemos más de mil setecientas zonas arqueológicas conocidas, de las cuales hay diferentes niveles de información. De algunas sabemos sólo en dónde están, de otras tenemos un registro mínimo, y otras más están ampliamente documentadas, de todas ellas, trece ya están abiertas al público y estamos trabajando en otras cuatro (Ichkabal, Chakanbakán, Xcalacoco y Rovirosa) desde hace varios años, posiblemente en un futuro próximo existan las condiciones para abrirlas al público.

Por lo que es importante señalar que de las 1,700 conocidas en todo el estado, sólo 14 se encuentran abiertas al público, y no existe ni el potencial para restaurarlas ni para negociar con los ejidatarios de tal forma que se vean beneficiados con abrirlas al público. 


\section{Cuadro 1}

\section{AFLUENCIA DE VISITANTES A LAS ZONAS ARQUEOLÓGICAS DE QUINTANA ROO, 2008-2014}

\begin{tabular}{|l|c|c|c|c|c|c|c|}
\hline \multicolumn{1}{|c|}{ ZONA } & $\mathbf{2 0 0 8}$ & $\mathbf{2 0 0 9}$ & $\mathbf{2 0 1 0}$ & $\mathbf{2 0 1 1}$ & $\mathbf{2 0 1 2}$ & $\mathbf{2 0 1 3}$ & $\mathbf{2 0 1 4}$ \\
\hline ERQUEOLÓGICA Rey & 8,308 & 7,035 & 7,296 & 8,144 & 12,047 & 14,109 & 12,742 \\
\hline San Gervasio & 100,186 & 80,198 & 137,895 & 137,080 & 151,809 & 171,168 & 186,970 \\
\hline Xel-Há & 2,252 & 1,808 & 2,198 & 1,874 & 2,429 & 2,037 & 2,285 \\
\hline Tulum & $1,348,036$ & 938,377 & $1,046,125$ & $1,085,288$ & $1,199,312$ & $1,289,343$ & $1,391,542$ \\
\hline Cobá & 355,531 & 306,222 & 323,079 & 400,641 & 473,259 & 422,370 & 417,141 \\
\hline Chacchoben & 9,238 & 33,769 & 66,618 & 56,167 & 60,898 & 55,278 & 54,125 \\
\hline Muyil & 5,100 & 3,940 & 2,878 & 2,691 & 5,187 & 5,803 & 10,223 \\
\hline Oxtankah & 10,845 & 9,377 & 8,492 & 8,720 & 9,508 & 8,736 & 7,580 \\
\hline Kohunlich & 26,720 & 27,993 & 51,066 & 50,515 & 34,324 & 27,635 & 31,810 \\
\hline Dzibanché & $\mathbf{6 , 9 0 3}$ & 8,883 & 15,961 & 16,140 & 11,541 & 10,046 & 11,024 \\
\hline Kinichná & 5,500 & 100 & 0 & 0 & 0 & 0 & 0 \\
\hline El Meco & nd & nd & 6,745 & 10,330 & 15,796 & 13,752 & 17,169 \\
\hline Xcaret & nd & nd & 20 & 30 & 261 & 118 & 91 \\
\hline \multicolumn{1}{|c|}{ TOTAL } & $\mathbf{1 , 8 7 8 , 6 1 9}$ & $\mathbf{1 , 4 1 7 , 7 0 2}$ & $\mathbf{1 , 6 6 8 , 3 7 3}$ & $\mathbf{1 , 7 7 7 , 6 2 0}$ & $\mathbf{1 , 9 7 6 , 3 7 1}$ & $\mathbf{2 , 0 2 0 , 3 9 5}$ & $\mathbf{2 , 1 4 2 , 7 0 2}$ \\
\hline
\end{tabular}

Fuente: Indicadores turísticos 2000-2014 (SECTUR, 2014).

En el sureste de México, una comunidad maya ${ }^{10}$ que se encuentra en las cercanías de uno de los cientos de cenotes que hay en el estado de Quintana Roo, pero que, paradójicamente, son apenas conocidos en forma pública, recientemente encontró restos de cerámica, esculturas pequeñas, algunos relieves, y lo que según afirma la comunidad, «piedritas de colores». Esta comunidad expresó también que están buscando la manera de construir un aviario para un ecoturismo arqueológico.

De lo anterior, la líder de la comunidad menciona lo siguiente:

[...] yo creo que sí es posible que nos organicemos para que se promueva el lugar y que vengan turistas porque no es nada más las piedras que tiene que conocer, sino también lo bonito del cenote, en donde se puede nadar o pasear por los alrededores, hay mucha planta medicinal que es desconocida y también lugarcitos donde se puede hacer deporte [...] obvio todo tiene que ser con respeto a la naturaleza porque para nosotros el monte está vivo y es sagrado, todo se lo debemos a él, y esto lo tendrán que aprender los turistas que vengan, no nada más importa el dinero o venirse a tomarse fotos y ya, sino que aprendan lo que aquí aún vive y que nos heredaron nuestros tatarabuelos mayas (M-51-CM) ${ }^{11}$.

10 Los autores del presente trabajo agradecen a las comunidades visitadas por su apoyo y facilidades para obtener sus opiniones y experiencias, así como a los arqueólogos que colaboraron, poniendo a disposición su experiencia laboral en la región.

11 La nomenclatura de los testimonios es la siguiente: $\mathrm{M}=$ mujer, $\mathrm{H}=$ hombre, número arábigo=edad, siglas del caso referido. 
No menos importante es citar el testimonio de un arqueólogo independiente (no afiliado a ninguna institución educativa o centro de investigación) sobre uno de estos casos de estudio que se estaba investigando al momento de la presente investigación, como se describe abajo:

[...] el hecho es de que al saber de la existencia de este lugar, y contra lo que establece el método científico que te enseñan en la universidad y la disciplina, primero me fui involucrando poco a poco con la gente del lugar, antes que ir directamente a la zona arqueológica. Así, pude darme cuenta de que las tradiciones orales, cosmovisión y costumbres de la comunidad constituyeron el marco de referencia simbólico que me ayudó a interpretar lo que ya posteriormente fui a ver a la zona arqueológica. Me di cuenta, por lo tanto, de que los lugares arqueológicos no son objetos de estudio, sino sujetos de diálogo. Sin la mediación de la comunidad y del gran conocimiento que aún conserva, jamás hubiera podido ir más allá de lo que los lentes del racionalismo moderno me dejarían ver, es decir, una miopía ante la vasta riqueza simbólica del lugar.

En general, se aprecia que en tiempos de la actual globalización económica es el mercado lo que está reestructurando estas relaciones, así como la adopción gerencialista en la regulación del patrimonio cultural y arqueológico, como se muestra enseguida.

\subsection{El Instituto ¿Nacional? de Antropología e Historia: hacia un gerencialismo arqueológico}

De acuerdo con lo dicho en el punto anterior, si bien en México la gestión de las zonas arqueológicas del país ha estado a cargo del INAH -organismo gubernamental decisorio en la política cultural y arqueológica nacional desde mediados de los setenta-, verdad es también que en la actualidad el desempeño de esta institución ha sido criticado, sobre todo por su falta de flexibilidad en apoyo al desarrollo de la economía social de las comunidades que se encuentran situadas en y alrededor de las zonas arqueológicas (Woynar, 2003). Basta con mencionar al respecto que a pesar de que el Instituto reporta 187 zonas arqueológicas registradas y abiertas al público, sólo 8 de éstas se encuentran reconocidas en la Lista del Patrimonio Mundial de la Organización de las Naciones Unidas para la Educación, la Ciencia y la Cultura (UNESCO), dejando así a México por debajo de países como Perú y Guatemala.

Otro de los problemas que ha acompañado a la tarea de este Instituto es su falta de coordinación con los estados, municipios y actores locales para mejorar la gestión administrativa y actualización del marco legal y normativo que descentralicen el poder históricamente concentrado en el mismo. Su excesiva burocratización administrativa ha sido bandera política que justifica la actual adopción de una visión gerencialista por encima de los criterios académicos provenientes del campo de expertis universitaria para la toma de decisiones sobre las acciones a emprender en la cultura y zonas arqueológicas del país (Ligorred, 2013). 
La nueva visión gerencialista del Instituto sobre el patrimonio cultural y arqueológico nacional, es producto de la adopción economicista desarrollada en apartados iniciales de este trabajo. Este cambio de la cultura, en cuanto valor económico, implica una diferenciación jerárquica inequitativa, ya que los «grandes» sitios arqueológicos -comúnmente relacionados con colosales pirámides- son motivo de apoyo en recursos y promoción turística mundial ${ }^{12}$; en cambio, los de «menor» rango - pequeños templos, como los Teocallis, por ejemplo-, son escasamente apoyados, perdiéndose así el potencial de información de inigualable valor histórico. Por ello Gómez (2007), al citar a Becerril (2000:217), menciona que:

[...] tradicionalmente la ineficacia de la administración gubernamental no sólo ha impedido la participación de otros intereses; también, la burocracia que caracteriza sus acciones y la inevitable corrupción implícita han sido factores de importancia al privar y destruir el patrimonio, pues sus posibilidades de respuesta siempre han sido rebasadas por la magnitud del problema, ya que [...] a pesar de la celebración de los convenios de colaboración entre las autoridades federales y los Estados, la participación de las instancias locales y la necesaria descentralización [...] es todavía escasa.

Por estas razones el INAH enfrenta reivindicaciones comunitarias que exigen la repatriación de las zonas arqueológicas ya que no reciben una indemnización digna debido a una falta de conocimiento de los que dirigen al Instituto sobre la riqueza del patrimonio, y la desconfianza de que sean las propias comunidades en hacerse cargo, como empresa social, del desarrollo turístico local (García, 2008). Estas afirmaciones deben ser profundizadas más a fondo, desde la perspectiva subjetiva de los locatarios.

Por ejemplo, en el municipio de Puerto Morelos se ubica una reserva constituida como Asociación Civil e integrada por 16 empleados. Es autofinanciable y abarca a 500 hectáreas de selva. Sus integrantes están interesados en realizar proyectos que les permitan conservar los lugares donde se han encontrado vestigios arqueológicos.

En entrevistas a los responsables de la reserva, ellos comentaron que están efectuando las gestiones necesarias para quedarse con el resguardo de la zona arqueológica, ya que personal del INAH fue a realizar las investigaciones pertinentes, pero se querían llevar las vasijas que encontraron; sin embargo, el dueño de la reserva no lo permitió, y les pidió que lo que se encontrara se dejara en su lugar y que la comunidad lo resguardaría, tal como se expresa en el testimonio siguiente:

No confiamos en la burocracia del INAH, ya que son muy lentos y muchos los trámites para los permisos, además de que no nos reconocen como herederos del

12 Esta visión es la que justifica que el INAH acepte licitaciones para el empleo de luz y sonido en las pirámides de El Castillo de Chichen Itzá en la Península de Yucatán, y de la Pirámide del Sol en Teotihuacán, Estado de México, como apertura a la privatización de estas zonas arqueológicas (véanse: La Jornada: «Hacen las primeras pruebas de show multimedia en Teotihuacán, en: http://www.jornada.unam. mx/2015/12/21/cultura/a05n1cul; y Diario de Yucatán: «Así luce «Noches de Kukulcán» en Chichén Itzá», en: http://yucatan.com.mx/merida/turismo/asi-luce-noches-de-kukulcan-en-chichen-itza, ambas consultadas el 14 de enero de 2016). 
lugar, y así nos quieren luego expropiar el terreno, y en lo que se tardan, estamos a expensas de los saqueadores, entonces preferimos tomar nosotros mismos manos a la carta y cuidar la zona y lo que haya en ella (H-32-RE).

Actualmente aún no se han rescatado los vestigios de la zona; no obstante, la reserva manifestó su interés de realizar algunos acompañamientos, específicamente con arqueólogos, con la finalidad de dar a conocer los hallazgos a través del manejo de pequeños grupos interesados en el turismo arqueológico, esto permitirá mantener el lugar, y lo más importante: que no se vuelva un lugar de visita para gran cantidad de personas, sino que se conserve lo místico y natural que caracteriza a estos lugares. Finalmente, el INAH permitió las visitas, aunque prohibió investigaciones sin su autorización.

Y así como el caso antes citado, existen una gran variedad de lugares por todo el país donde concurre el interés de compartir lo que se encuentran en sus tierras, pero sin que esto sea explotado por terceros y ellos no reciban ningún beneficio.

Situado cerca de Akumal, lugar situado en la Riviera Maya, los dueños de 300 hectáreas son nietos de «chicleros» de la zona. En corto tiempo el lugar abrirá como bioparque, y una de las modalidades que ofrecerá son expediciones arqueológicas, ya que han hallado vestigios arqueológicos; sin embargo, el dueño comentó que cuando reportó el hallazgo al INAH, personal del Instituto se llevó una vasija que se había encontrado, dejaron la documentación de que se halló en ese lugar, pero no se han realizado más investigaciones. Uno de los testimonios expresa lo siguiente:

Nos interesa ver cómo le podemos hacer para conseguir recursos y apoyos de otras organizaciones que no sean del gobierno para que podamos construir un museo que esté administrado por la comunidad, y no por el gobierno, porque para nosotros es muy importante conservar y difundir a los turistas y a los niños y niñas de nuestra propia comunidad el pasado de nuestros ancestros y el gran conocimiento que tenían, para que así ya no nos vean los turistas como muñecos de aparador o algo así pues (M-28-EP).

Asimismo, esta organización muestra el desarrollo propio de habilidades para la promoción del lugar a través del uso de las redes sociales, lo cual es un indicador de un empoderamiento significativo y al margen de los servicios educativos de la zona, tal como lo señaló una de las entrevistadas:

[...] ya hasta estamos usando el face para darnos a conocer a la gente y atraer así más turismo. Ahí en el face, se muestran fotos de la zona y mucha gente pregunta cómo llegar acá, qué más hay, y cuando les decimos de los lugares naturales que hay alrededor se muestran muy interesados y más porque sólo se les pide una aportación voluntaria en dinero o especie (M-25-EP).

Como se aprecia, indudablemente los alcances y límites de la política del turismo arqueológico nacional son determinantes para el desarrollo económico de las localidades comunitarias del estado, tema del subapartado siguiente. 


\subsection{Limitaciones y obstáculos en la política del turismo arqueológico nacional}

Los recursos arqueológicos que se encuentran en el estado de Quintana Roo, así como todos los vestigios registrados por el INAH, se encuentran categorizados dentro del patrimonio cultural junto con otras actividades como el fomento al teatro, la literatura, las costumbres, las tradiciones, etc., incluyendo a la misma educación. Todo se encuentra contemplado dentro de la política cultural y, por lo tanto, el presupuesto destinado a la preservación e investigación de vestigios arqueológicos es limitado. Como apunta Woynar (2003), las pocas zonas arqueológicas que ya se encuentran en conservación se identifican como aquellas que hay que mantener en especial cuidado por su potencial para atraer ingresos, pero no por su valor cultural.

Como se ha defendido a lo largo de este trabajo, el turismo arqueológico es una de las categorías más importantes de México. No obstante, ha enfrentado problemas financieros que limitan su potencial y desarrollo. Beltrán y Rojas (1998), mencionan que la dependencia al presupuesto federal ocasiona el estancamiento en el mantenimiento e investigación de nuevas zonas arqueológicas, así como una baja calidad de servicio para los turistas.

El Plan Estatal de Desarrollo denominado «Plan Quintana Roo 2011-2016», busca impulsar programas orientados a preservar, promover, fomentar y difundir el patrimonio cultural de los 10 municipios que conforman al estado. Sin embargo, los datos del INAH indican que hay 220 sitios arqueológicos en mar y 260 en tierra, por lo que hay mucho por hacer en investigación e interpretación arqueológica, ya que sólo se ha estudiado el $10 \%$ de esta extensa riqueza, lo que contradice los objetivos del Plan Estatal.

Por ello es importante tomar en cuenta que las zonas arqueológicas merecen ser tratadas desde un punto de vista más particular, y no como parte de los objetivos del patrimonio cultural. Además, el estado cuenta con 300 comunidades indígenas y alrededor de 163,447 hablantes de lengua maya, lo que representa al $12.3 \%$ de la población total del estado. Dichas comunidades pueden obtener beneficios de las zonas arqueológicas a cambio del apoyo para la conservación de su biodiversidad.

Lo antes afirmado es de vital relevancia en cuestión del turismo. De acuerdo con los Indicadores Básicos del Desempeño Ambiental 2010 de la Secretaría de Medio Ambiente y Recursos Naturales (SEMARNAT), en los periodos comprendidos entre 2000-2001 y 2009-2010, el promedio de turistas nacionales y extranjeros que visitaron las zonas del arrecife de coral mexicano fue de 10.9 millones al año, respecto de un total de 43.8 millones de turistas. En esos mismos periodos, $57.4 \%$ de ese total, visitaron El Caribe (SEMARNAT, 2012:168).

A raíz de las cifras arriba citadas, la problemática identificada por aquella dependencia federal fue que: «Los turistas afectan los arrecifes coralinos por el pisoteo, colecta de ejemplares de coral y otras especies, así como los daños por las embarcaciones que los transportan. Favorecen también la sobreexplotación de productos pesqueros y la descarga de aguas residuales sin tratamiento de los establecimientos turísticos» (SEMARNAT, 2012:168). Lo que no específica la SEMARNAT es que esta problemática ambiental es generada por las grandes firmas hoteleras y de agencias de viajes instaladas en la costas mexicanas de El Caribe, el Golfo de México y el Pacífico, confirmando 
así lo aseverado en los primeros apartados de este trabajo: la falta de una relación cognoscitiva y consciente del turista con respecto a la cultura local a donde llega. Y estas empresas tienen gran responsabilidad en ello.

\section{CONCLUSIONES}

Este trabajo no sólo muestra la importancia de buscar la preservación y difusión pública de las zonas arqueológicas de la Riviera Maya, sino más importante aún: promover un cambio en la agenda de las políticas del turismo nacional e internacional a fin de que se destinen acciones y recursos con base en el reconocimiento previo del concepto, de la forma de ser y hacer turismo desde la perspectiva de las comunidades locales.

Se trata de establecer otra forma de organización y orientar el mercado turístico nacional en beneficio económico de las comunidades y no exclusivamente de las empresas que monopolizan el sector. Expone, además, la urgente necesidad de un cambio en la cultura y percepción de los agentes, que reconozcan a esta actividad turística local como un proceso de autoconocimiento y autoconciencia, más allá del vacuo turismo mediático, consumista y mercantil.

Pese a lo que comúnmente se cree, existen un número importante de zonas arqueológicas no reconocidas por el INAH, pero sí por parte de los lugareños de las comunidades rurales. Sin embargo, debido a que entre ellos no existe confianza para reportar sus descubrimientos a las autoridades de este Instituto, han optado por mantener el silencio, pues no ven una posibilidad de trabajo turístico, ya que desde su punto de vista el llevar a personas al interior de las zonas arqueológicas en sus comunidades podría catalogarse como «turismo ilegal».

Por lo que se concluye que han pasado décadas sin que exista participación de los organismos tanto estatales como municipales para la gestión del patrimonio arqueológico, y los pocos esfuerzos se han traducido a favor de seguir con el monopolio del INAH. Los testimonios de los lugares analizados muestran que existe potencial para realizar turismo arqueológico desde una perspectiva más responsable e inclusiva desde lo local.

De seguir sin apoyo por parte de los diferentes gobiernos, los vestigios están condenados al olvido y destruidos por la construcción de desarrollos habitacionales. Se apoya el argumento de considerar al patrimonio arqueológico dentro de los programas de ordenamiento territorial y desarrollo urbano.

Se requiere generar sinergias de relaciones con otros actores locales y estatales, como las universidades e institutos de investigación, en el diseño de planes de estudio desde la problemática enfrentada por estas comunidades a fin de formar y empoderar a las mismas en el desarrollo de habilidades y conocimientos sobre elaboración y gestión de proyectos culturales con base en el manejo de las redes sociales, pero fundados en una epistemología desde la propia cosmovisión y cultura.

Buscar el apoyo financiero internacional para la construcción de museos comunitarios con la finalidad de que sirvan para la realización de prácticas escolares en las reservas, lo que permitiría al turismo tener contacto directo con arqueólogos y hacer conciencia sobre el valor del patrimonio cultural en cualquier comunidad. Se advirtió el apoyo de estas propuestas por algunos arqueólogos que estarían en la disposición de trabajar con nuevos 
proyectos de inclusión de la comunidad. Sin embargo, hasta ahora no se han observado proyectos importantes o acciones a realizar por parte de los actores sociales, ya que se trabaja de forma aislada.

Se propone que a partir de la fuerza que han tomado organizaciones civiles deben conformarse en grupos que comiencen a interactuar entre ellos para la organización de eventos informativos y de educación, e incluir aquellos grupos identificados en redes sociales para la difusión en favor de la conservación del patrimonio arqueológico, así como a los ejidatarios e integrantes de comunidades y con ello empezar a crear una organización con acciones claras que lleguen a ser representativas del país y escuchadas por los diferentes niveles de gobierno.

De no atenderse estas problemáticas en el corto plazo, se está en el riesgo de ser también responsables no sólo de la dependencia económica de nuestra riqueza cultural y natural, sino también del genocidio de lo que constituye las raíces éticas de nuestro pasado y presente cultural. Las generaciones futuras y la historia, nos lo demandará.

\section{REFERENCIAS}

ALTSCHULER, B. y CASALIS, A. (2006): «Aportes del desarrollo local y la economía social a una estrategia nacional de desarrollo», en García Delgado, Daniel y Luciano Nosetto, (Comps.) (2006): El desarrollo en un contexto postneoliberal. Hacia una sociedad para todos. Buenos Aires, Colección Transformaciones, CICCUS-FLACSO, pp. 1-46.

BAUMAN, Z. (2001): La globalización. Consecuencias humanas. México, Edit. Fondo de Cultura Económica.

BLANCO, H.F.J. (2015): Libro blanco de los destinos turísticos inteligentes: Estrategias y soluciones para fomentar la innovación en el turismo digital. México, Edit. Empresarial, primera edición, junio.

CAMBEROS SÁNCHEZ, M.T. (2011): «Empoderamiento femenino y políticas públicas. Una perspectiva desde las representaciones sociales de género», Entramado, n 7 , pp. 40-53.

CAÑADA, E. (2007): Turismo y desarrollo: herramientas para una mirada crítica. Managua, Nicaragua, Edit. Enlace.

CARBALLO-SANDOVAL, A. (2005): «Análisis de un modelo de desarrollo ecoturístico en Quintana Roo», en Teoría y Praxis I. México, Edit. Universidad de Quintana Roo, pp. 31-47.

DIARIO OFICIAL DE LA FEDERACIÓN (1993): Reglamento de la Ley Federal sobre Monumentos y Zonas Arqueológicos, Artísticos e Históricos. México, Edit. Gobierno Federal.

DÍAZ-CARRIÓN, I.A. (2014): «Ecoturismo y vida cotidiana de las mujeres en Sontecomapan, Veracruz, México», en Cuadernos de Turismo, n 34, pp. 69-88.

DICCIONARIO DE LA REAL ACADEMIA ESPAÑOLA (2015): Disponible en http:// Www.rae.es/recursos/diccionarios/drae

FERNÁNDEZ ARUFE, J. E.; GÓMEZ GARCÍA, J.M.; JUSTE CARRIÓN, J.J. (2011): «Economía social y desarrollo local/rural. Un análisis de sus sinergias», Estudios de Economía Aplicada, $\mathrm{n}^{\circ}$ 29, pp. 189-221. 
FERNÁNDEZ, G. y GUZMÁN, R.A. (2002): «Turismo: patrimonio cultural y desarrollo sustentable», en Caminhos de Geografia, Revista On-line, Instituto de Geografía UFU, pp. 1-19. Disponible en http://coalicionventanaverraco.org/files/artigo01_vol07.pdf

FUKUYAMA, F. (1992): The end of history and the last man. New York, Edit. Macmillan. GARCÍA, L.A. (2008): «Patrimonio cultural: diferentes perspectivas», en Arqueweb, Revista sobre arqueología en Internet, $\mathrm{n}^{\circ} 9$.

GIDDENS, A. (1993): Consecuencias de la modernidad. Madrid, Edit. Alianza Universidad.

GÓMEZ, G.F., (2007): «Análisis del desarrollo disciplinar de la arqueología mexicana y su relación con el patrimonio arqueológico en la actualidad», en Cuicuilco. México, Edit. UNAM, septiembre-diciembre, pp. 219-224.

GOODSON, L. y PHILLIMORE, J. (Eds.) (2004): Qualitative Research In Tourism: Ontologies, Epistemologies \& Methodologies. London and New York, Edit. Routledge.

GUZMÁN HERNÁNDEZ, C., MENDOZA GARDUÑO, M. y ZIZUMBO VILLAREAL, L. (2009): «Reflexión crítica sobre el consumo turístico», Estudios y perspectivas en Turismo, vol. 18, pp. 691-706.

HINKELAMMERT, F. (2001): El nihilismo al desnudo. Los tiempos de la globalización. Santiago, Chile, Edit. LOM.

HIRSCH, J. (1996): Globalización, capital y Estado. México, Edit. Universidad Autónoma Metropolitana-Xochimilco.

HUSSEIN MUSTAFA, M. (2010): «Tourism and globalization in the Arab World», en International Journal of Bussines and Social Science, vol. $1, \mathrm{n}^{\circ} 1$.

INEGI, (2015): Principales resultados de la Encuesta Intercensal 2015: Quintana Roo. México. Disponible en http://internet.contenidos.inegi.org.mx/contenidos/productos//prod_serv/contenidos/espanol/bvinegi/productos/nueva_estruc/inter_censal/estados2015/702825080136.pdf

LIGORRED PERRAMON, J. (2015): «La gestión del patrimonio arqueológico en los pueblos vivos», en Segundo Encuentro Nacional de Gestión Cultural: diversidad, tradición en la gestión cultural, Tlaquepaque, Jalisco, 14-17 de octubre de 2015.

LÓPEZ OLIVARES, D. (2006): «El modelo turístico de carácter sistémico e integrado como facilitador del desarrollo en los países centroamericanos: el caso de Nicaragua», Documents d'Anàlisi Geográfica, n 47, pp. 69-91.

MAGAÑA-CARRILLO, I. (2009): «La política turística en México desde el modelo de calidad total: un reto de competitividad», Economía, Sociedad y Territorio, vol. IX, $\mathrm{n}^{\circ} 30$, pp. 515-544.

MARX, K. (1985): El Capital. México, Siglo XXI.

MENDIGUREN, J., ETXEZARRETA, E., GURIDI, A. (2009): «Economía social, empresa social y economía solidaria: diferentes conceptos para un mismo debate», en Papeles de Economía Solidaria, $\mathrm{n}^{\circ} 1$, junio.

MONTERRUBIO J.C., MENDOZA M.M., FERNÁNDEZ M.J. y GULLETE G.S. (2011): «Turismo y cambios sociales. Estudio cualitativo sobre percepciones comunitarias en Bahías de Huatulco, México», Cuadernos de Turismo, n² 28, pp. 171-189.

MORÉRE MOLINERO, N. y JIMÉNEZ GUIJARRO, J. (2006): «Análisis del Turismo Arqueológico en España. Un estado de la cuestión», Estudios Turísticos, n $^{\circ} 171$, pp. 115-139. 
NEAMTAN, N. (2009): «Social Economy: concepts and challenges», eUniversitas Forum, vol. 1, $\mathrm{n}^{\circ} 3$, December.

ORGANIZACIÓN MUNDIAL DEL TURISMO (2011): El turismo hacia el 2030. Madrid, Edit. Organización Mundial del Turismo.

PALAFOX-MUÑOZ, A. (2013): «El turismo como eje de acumulación», en: Ernest Cañada (Coord.): Turismo en Centroamérica. Un diagnóstico para el debate. Nicaragua, Edit. Enlace, pp. 15-16.

PALAFOX-MUÑOZ, A. y MARTÍNEZ-PEREZCHICA, M. G. (2015): «Turismo y nueva ruralidad: camino a la sustentabilidad social», Letras Verdes, n $^{\circ} 18$, pp. 138-159.

PERIC, V. (2005): «Tourism and globalization, Managing the process of Globalization in new and upcoming EU members», en Proceedings of the 6th International Conference of the Faculty of Management Koper Congress Centre Bernadin. Slovenia, November, pp. 24-26.

SÁNCHEZ TOVAR, L. (2009): «Turismo y comunidad receptora. Un estudio en la costa venezolana. Fermentum», Revista Venezolana de Sociología y Antropología, n 19, pp. 79-101.

SANTANA TAKLAVERA, A. (2003): «Turismo cultural, culturas turísticas», Horizontes Antropológicos. Porto Alegre, año 9, n² 20, octubre, pp. 31-57.

SECTUR, (2014): Compendio turístico del turismo en México, 2014. Disponible en: http:// www.datatur.sectur.gob.mx/SitePages/CompendioEstadistico.aspx

SEMARNAT (2012): Indicadores Básicos del Desempeño Ambiental 2010. México, Edit. Secretaría de Medio Ambiente y Recursos Naturales.

VALDERRAMA, S. A; FERNÁNDEZ, X. R.; NEME, C. O., y VÁZQUEZ, L. A. M. (2013): «Matriz de Incidencias para las Organizaciones de la Sociedad Civil: Una propuesta de análisis», Revista Administración y Organizaciones, año 16, n 31, pp. 35-69.

VALENCIA, I. (2013): «Entrevista con Adriana Velázquez Morlet, Delegada del Centro INAH Quintana Roo», Cuiculco, n 56, pp. 261-267.

VARGAS LLOSA, M. (2000): Culturas y globalización. Santafé de Bogotá, Edit. El Tiempo.

VELA, P. F. (2013): «Un acto metodológico básico de la investigación social: La entrevista cualitativa», en Tarres (Coord.): Observar, escuchar y aprender, sobre la tradición cualitativa en la investigación social. México, Edit. FLASCO/COLMEX/ Porrúa, pp. 63-95.

WOYNAR, M. (2003): «Arqueología y problemática social: Hacia un manejo de los recursos arqueológicos con mayor colaboración de las comunidades», en XVI Simposio de Investigaciones Arqueológicas en Guatemala, 2002. Guatemala, Edit. Museo Nacional de Arqueología y Etnología, pp. 36-47.

ZHAO, W. y LI, X. (2006): «Globalization of Tourism and Third World Tourims Development: a political economy perspective», en Chinese Geographical Science, año, 16 $\mathrm{n}^{\circ}$ 3. Changchun, pp. 203-210.

ZIZUMBO VILLAREAL, L. (2010): «Turismo y economía social, nuevas formas organizativas de trabajo para el desarrollo sustentable», en Monterroso y Zizumbo (Coord.): Contra la domesticación del turismo, los laberintos del turismo rural. México, Edit. Universidad Autónoma del Estado de México. 


\section{FUENTES DE INTERNET}

DIARIO DE YUCATÁN. «Así luce «Noches de Kukulcán» en Chichén Itzá», consultada el 14 de enero de 2016. Disponible en http://yucatan.com.mx/merida/turismo/asi-lucenoches-de-kukulcan-en-chichen-itza

LA JORNADA. «Hacen las primeras pruebas de show multimedia en Teotihuacán», consultada el 14 de enero de 2016. Disponible en http://www.jornada.unam.mx/2015/12/21/ cultura/a05n1cul

LEY FEDERAL DE TURISMO. Consultada el 13 de enero de 2016. Disponible en www3. diputados.gob.mx/.../Ley_Federal_Turismo.pdf

THE GUARDIAN. «Justin Bieber thrown out of Mexico's Tulum ruins, official says», consultado el 13 de enero de 2016. Disponible en http://www.theguardian.com/ music/2016/jan/08/justin-bieber-tulum-mayan-ruins-mexican-official-says_ 